Available online on 15.12.2019 at http://jddtonline.info
Open Access to Pharmacentical and Medical Research
unrestricted non-commercial use, provided the original work is properly cited

Open 1 Access

Research Article

\title{
Instrumental Characterization and Antibacterial Investigation of Silver Nanoparticles Synthesized From Garcinia Kola Leaf
}

\section{AKINTELU Sunday Adewale ${ }^{1 *}$, FOLORUNSO Aderonke Similoluwa ${ }^{2}$ and ADEMOSUN Olabisi Theresa ${ }^{3}$}

${ }^{1}$ Department of Pure and Applied Chemistry, Ladoke Akintola University of Technology, Ogbomoso, Nigeria

${ }^{2}$ Department of Chemistry, Louisiana State University, Louisiana, USA

${ }^{3}$ Department of Chemical science, Covenant University, Otta, Nigeria

\begin{abstract}
The need to devise another method of synthesizing nanoparticles from sources that are eco-friendly, non-hazardous and cost effectiveness is of great importance in preventing environmental and health problems. The aim of this study was to evaluate the efficiency of Garcinia kola leaves as reducing and stabilizing agent for silver nanoparticles synthesis. The leaves of Garcinia kola obtained were authenticated, air dried, pulverized and extracted. The extract was mixed with aqueous solution of silver nitrate solution to form silver nanoparticles and were characterized using Ultra violet (UV) spectroscopy, Fourier transform infrared (FTIR) spectroscopy, Scanning electron microscopy (SEM), Transmission electron microscopy (TEM), Energy-dispersive X-ray spectroscopy (EDX) and X-ray diffraction (XRD). The antibacterial investigation of the synthesized silver nanoparticle was carried out following the disk diffusion method. UV analysis revealed the silver surface plasmon band at $425.18 \mathrm{~nm}$, The FTIR indicated $-\mathrm{OH},-\mathrm{C}=\mathrm{C}$ - and alkane as the functional groups responsible for the stabilization of the silver nanoparticle formed. The morphological assessment from SEM and TEM analysis confirmed that the silver nanoparticle formed are spherical in shape with an average particle size of $28.80 \mathrm{~nm}$.The EDX analysis ascertained that the silver surface plasmon resonance at $2.8-3.2 \mathrm{keV}$ was confirmed the reduction of silver ion $\left(\mathrm{Ag}^{+}\right.$to $\left.\mathrm{Ag}^{0}\right)$. The XRD study revealed the crystalline nature of the nanoparticles synthesized. The antibacterial investigation showed high inhibition against the growth of tested bacteria. This study ascertained that the green synthesis of silver nanoparticle without the use of harmful solvent that are offensive to the environment is achievable.
\end{abstract}

Keywords: Silver nanoparticles, Biosynthesis, Characterization, Antibacterial activity and Garcinia kola.

Article Info: Received 05 Oct 2019; Review Completed 16 Nov 2019; $\quad$ Accepted 21 Nov 2019; Available online 15 Dec 2019

Cite this article as:

Akintelu SA, Folorunso AS, Ademosun OT, Instrumental Characterization and Antibacterial Investigation of Silver Nanoparticles Synthesized From Garcinia Kola Leaf, Journal of Drug Delivery and Therapeutics. 2019; 9(6-s):58-64 http://dx.doi.org/10.22270/jddt.v9i6-s.3749

*Address for Correspondence:

AKINTELU Sunday Adewale, Department of Pure and Applied Chemistry, Ladoke Akintola University of Technology, Ogbomoso, Nigeria

\section{INTRODUCTION}

The demand for silver nanoparticles is increasing globally due to its wide application in medicine, food, electronics and agricultural industries. Nanoparticles are presently regarded as sustainable antimicrobial agent with remarkable potential to eradicate microbial multidrug resistance challenges and formation of microbial biofilm [1]. From the assessment of current antibiotic therapy, the restrictions and adverse effects associated with current antimicrobial agent calls for a timely development of novel brands of therapeutic agents with better efficacy from plant material[2,3].

The chemical approach of synthesizing nanoparticles which happened to be the most frequently used method involve uses of various organic solvents such as trisodium citrate, hydrazine, ascorbate, sodium borohydride e.t.c that are expensive and not environmental friendly as reducing agent

ISSN: 2250-1177
[3-6]. Hence, the need for earnest development of environmental, high yield and safer methods to replace the chemical reduction approach is imperative. This had led to the biosynthesis/green synthesis that deals with the use of plant's extract, microorganisms and yeast as reducing agent $[7,8]$.

However, the use of microbial sources as reducing agent in nanoparticles synthesis are limited due to cost of microbial isolation, high maintenance of culture media and sterile conditions required. Therefore, the use of plant's part remain a promising source of reducing agents in nanoparticles synthesis [9].

Garcinia kola is a medical plant usually found in western countries of African whose medicinal uses as antihypertensive, aphrodisiac and antimicrobial agent has been documented [21]. Therefore, this study aimed at the 
characterization and antibacterial study of silver nanoparticles synthesized using Garcinia kola leaf extract as reducing agent.

\section{MATERIALS AND METHODS}

\section{Collection, Identification and Extraction of Garcinia kola} leaves.

The leaves of Garcinia kola were collected from a local farm in Gbeleju village in Irele metropolis of Ondo state in Nigeria. The leaves were identified, air dried and pulverized into fine particles. The extraction of Garcinia kola leaves was done by transferring $200 \mathrm{~g}$ of pulverized particles into a beaker containing clean water at room temperature. The mixture was left for 48 hours for proper extraction with proper agitation at every 3 hours interval. The solution was filtered and the filtrate obtained was transferred into an amber colored sample bottle and kept in the refrigerator at $4^{\circ} \mathrm{C}$ for further analysis.

\section{Synthesis of silver nanoparticles using Garcinia kola leaf extract}

$1 \mathrm{mM}$ silver nitrate $\left(\mathrm{AgNO}_{3}\right)$ solution was prepared. The prepared $\mathrm{AgNO}_{3}$ solution and Garcinia kola leaf extract were thoroughly mixed together in ratio 1:5. The mixture was heated in a beaker at $45^{\circ} \mathrm{C}$ and stirred continuously at 800 rpm via magnetic stirrer. The colour of the solution changed to reddish brown after 2 hours. The mixture was filtered and the filtrate obtained was stored in a bark sample bottle and kept in the refrigerator prior further analysis.

\section{Characterization of synthesized silver nanoparticles}

The synthesized nanoparticles was scanned on the UV-1800 Shimadzu spectrophotometer at wavelength 200-700 nm and its UV spectrum was recorded. FTIR spectroscopy was adopted in determination of the functional groups present in the synthesized nanoparticles by scanning the formed nanoparticles on a FTIR spectrophotometer at wavelength $\left(500-4000 \mathrm{~cm}^{-1}\right)$. The morphological study of the synthesized nanoparticles were carried out by scanning synthesized nanoparticles on SEM and TEM machine. The composition of elements in the synthesized nanoparticles was determined via EDX spectrometer. The crystalline nature of the synthesized nanoparticles was examined through XRD pattern gotten from X-ray diffractometer (Rigaku-MiniFlex 600) in the range of 0 to $100^{\circ}$ at $2 \theta$.

\section{Bacterial strains used for the antibacterial screening}

The antibacterial screening of AgNPs was carried out against four clinical isolate bacterial strains Gram positive bacteria (Staphylococcus aureus and Bacillus cereus) and Gram negative bacteria (Pseudomonas aeruginosa and Escherichia coli).

\section{Antibacterial screening of AgNPs}

Each test bacterial strain was subcultured at $35{ }^{\circ} \mathrm{C}$ in Mueller-Hilton agar overnight and $5 \mathrm{ml}$ of saline water was used to harvest the bacterial growth. 50, 100 and $150 \mathrm{mg}$ of AgNPs were loaded on sterile filter paper discs to derive a final concentration of 50,100 and $150 \mathrm{mg} /$ disc. Fifteen ml of Mueller-Hilton agar medium was gently transferred into sterilized petric dishes, $15 \mathrm{ml}$ of seeded medium that was previously inoculated with bacterial suspension was added to the medium. The control was set up by loading filter paper discs with $8 \mathrm{mg}$ of Ciprofloxacin. The plates were placed in the refrigerator for two hours at $4^{\circ} \mathrm{C}$ to ensure thorough diffusion of the AgNPs. After two hours of diffusion the plates were incubated at $37^{\circ} \mathrm{C}$ for 24 hours. The inhibition zones observed were measured with transparent ruler and documented as the antibacterial activity of the AgNPs and control. This experiment was repeated twice.

\section{RESULTS AND DISCUSSION}

\section{UV-Spectroscopic Analysis of Synthesized Silver Nanoparticles}

The UV spectrum of the synthesized silver nanoparticles showed in Figure 1 indicated a wide surface plasmon band centered at $425.18 \mathrm{~nm}$, which pointed out the formation of silver nanoparticles in reaction mixture. This thereby, confirmed the bioreduction process of the silver nanoparticles via the extract. This finding is consistent with recent reports stating a plasmon peak at wavelength $445 \mathrm{~nm}$ and $415-420 \mathrm{~nm}$ as the UV absorption band for silver nanoparticles [10,11].

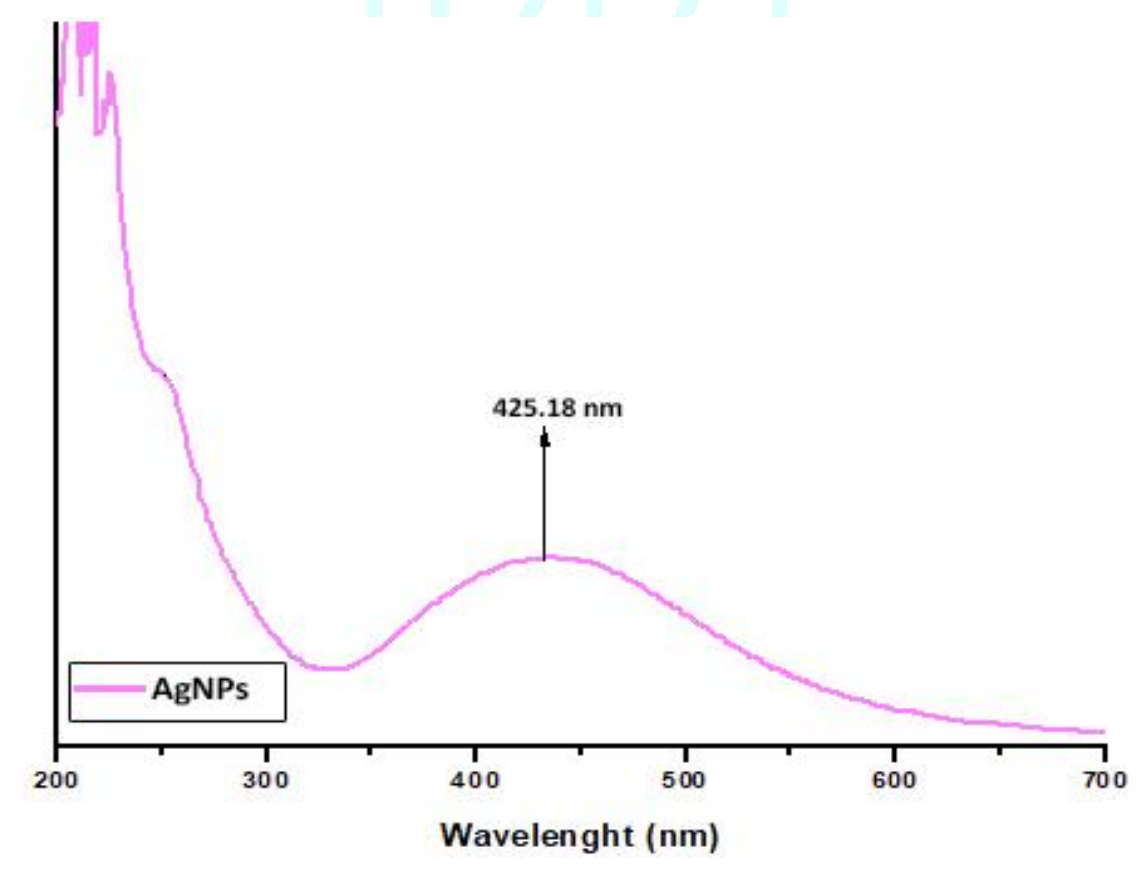

Figure 1 : UV spectrum of the synthesized silver nanoparticles 
FTIR Spectroscopic Analysis of Synthesized Silver Nanoparticles

The functional groups responsible for the binding and reduction of silver ion were identify from the FTIR spectra showed in Figure 2a and 2b. The FTIR spectra of Garcinia kola extract and synthesized silver nanoparticles revealed similar absorption bands at varying absorption wavelength $(3325.15,1652.29,660.42$ and 3347.45, 2982.23, 1648.32, $658.34 \mathrm{~cm}^{-1}$ respectively). These peaks in the infrared region of $3325-3347 \mathrm{~cm}^{-1}, 2982 \mathrm{~cm}^{-1}, 1652-1648 \mathrm{~cm}^{-1}$ and 658.34 - $660.42 \mathrm{~cm}^{-1}$ correspond to $-\mathrm{OH}$ functional groups of phenolic or alcohol, - $\mathrm{C}-\mathrm{H}$ of alkane, $\mathrm{C}=\mathrm{C}$ of alkene and bending vibration of $-\mathrm{C}-\mathrm{H}$ of alkane respectively. The presence of these functional groups confirmed that Garcinia kola leaf extract contains metabolites that are capable of serving as stabilizing and reducing agent for the synthesized silver nanoparticles. This study agree with recent studies that confirm $-\mathrm{OH}$ functional group as reducing agent in the synthesis of silver nanoparticle [11,12]

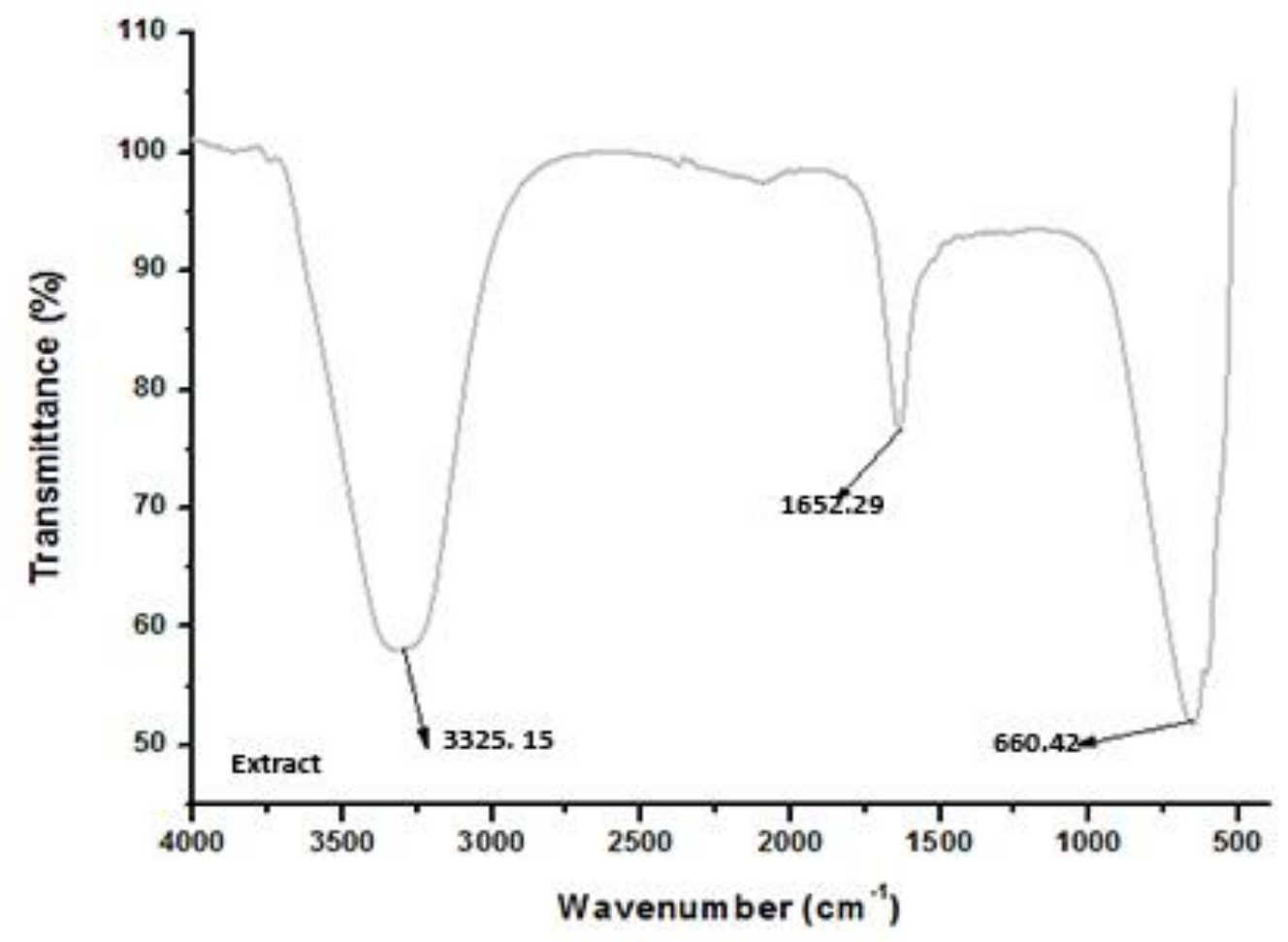

Figure 2a: FTIR spectrum of Garcinia kola leaf extract

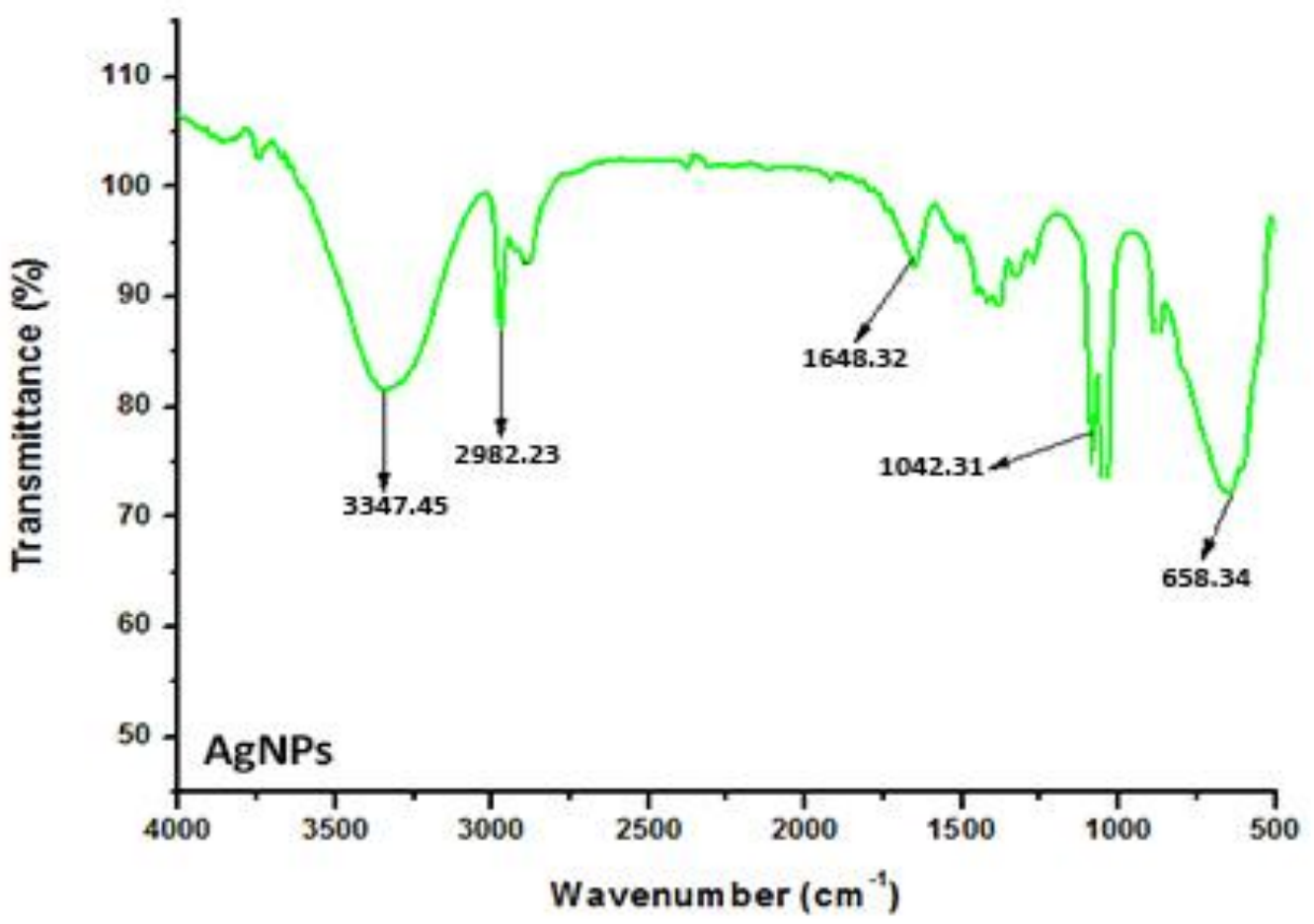

Figure 2b: FTIR spectrum of synthesized silver nanoparticles 


\section{SEM Analysis of synthesized silver nanoparticles.}

The morphology features of the synthesized silver nanoparticles obtained from SEM analysis displayed in the
SEM micrograph in Figure 3 confirmed a mono-disperse spherical particles. The data from the SEM study are related to the findings of $[13,14]$.

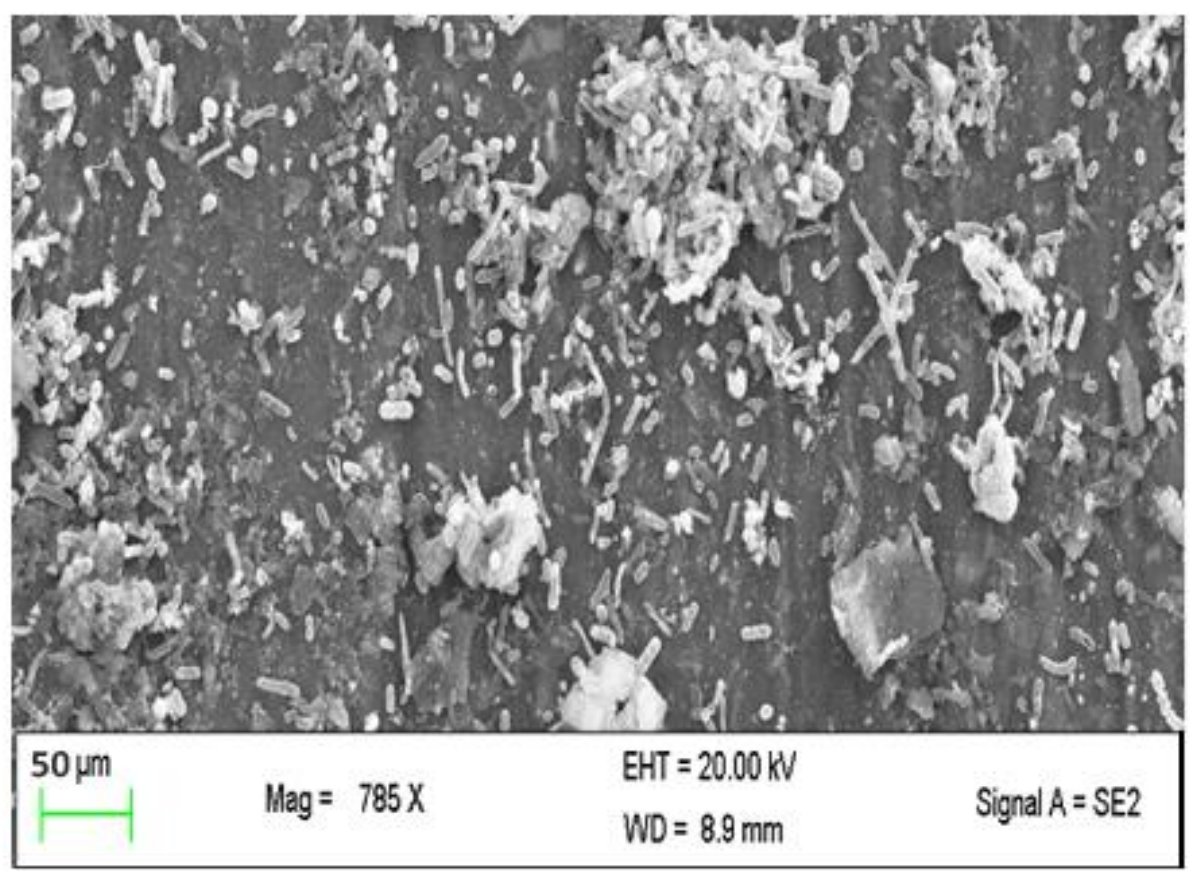

Figure 3: SEM micrograph of the synthesized silver nanoparticles.

TEM of the synthesized silver nanoparticles.

The TEM micrograph of the synthesized silver nanoparticles presented in Figure 4 revealed that the synthesized silver nanoparticles are properly dispersed, spherical and had particle size ranging from 18 to $38 \mathrm{~nm}$ with an average particle size of $28 \mathrm{~nm}$. This finding is in line with the findings of Balavijayalakshmi and Ramalakshmi 2019 which confirm that a spherical shape for silver nanoparticle [12].

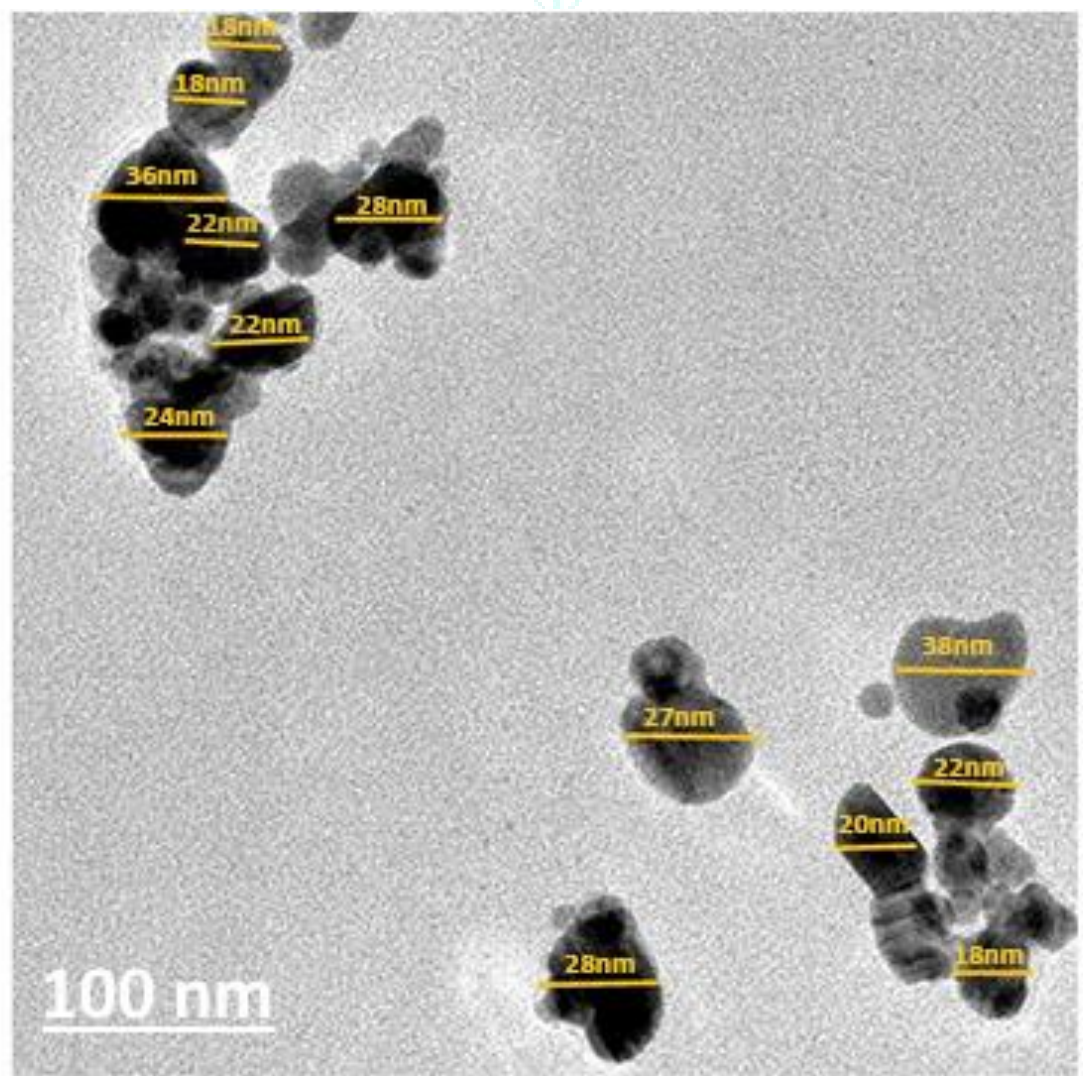

Figure 4: TEM micrograph of the synthesized silver nanoparticles. 


\section{EDX Analysis of Synthesized Silver Nanoparticles}

The EDX image of the synthesized silver nanoparticles showed in Figure 5 revealed a distinct peak of silver at 2.8$3.2 \mathrm{keV}$ which indicate the reduction of silver ion $\mathrm{Ag}^{+}$to $\mathrm{Ag}^{0}$ ). Also there are two other peaks at 0.8 and $1.4 \mathrm{keV}$ corresponding to carbon and oxygen respectively. The atomic percentage of silver, carbon and oxygen are $47.86 \%$ $32.09 \%$ and $20.05 \%$ respectively. The signal of carbon might have emanated from the adsorbed components of the coating material of the instrument while the signal of oxygen might have originated from atmospheric oxygen from air. Previous studies confirmed typical absorption peak around 2.5 KeV as silver Surface Plasmon Resonance [15-17].

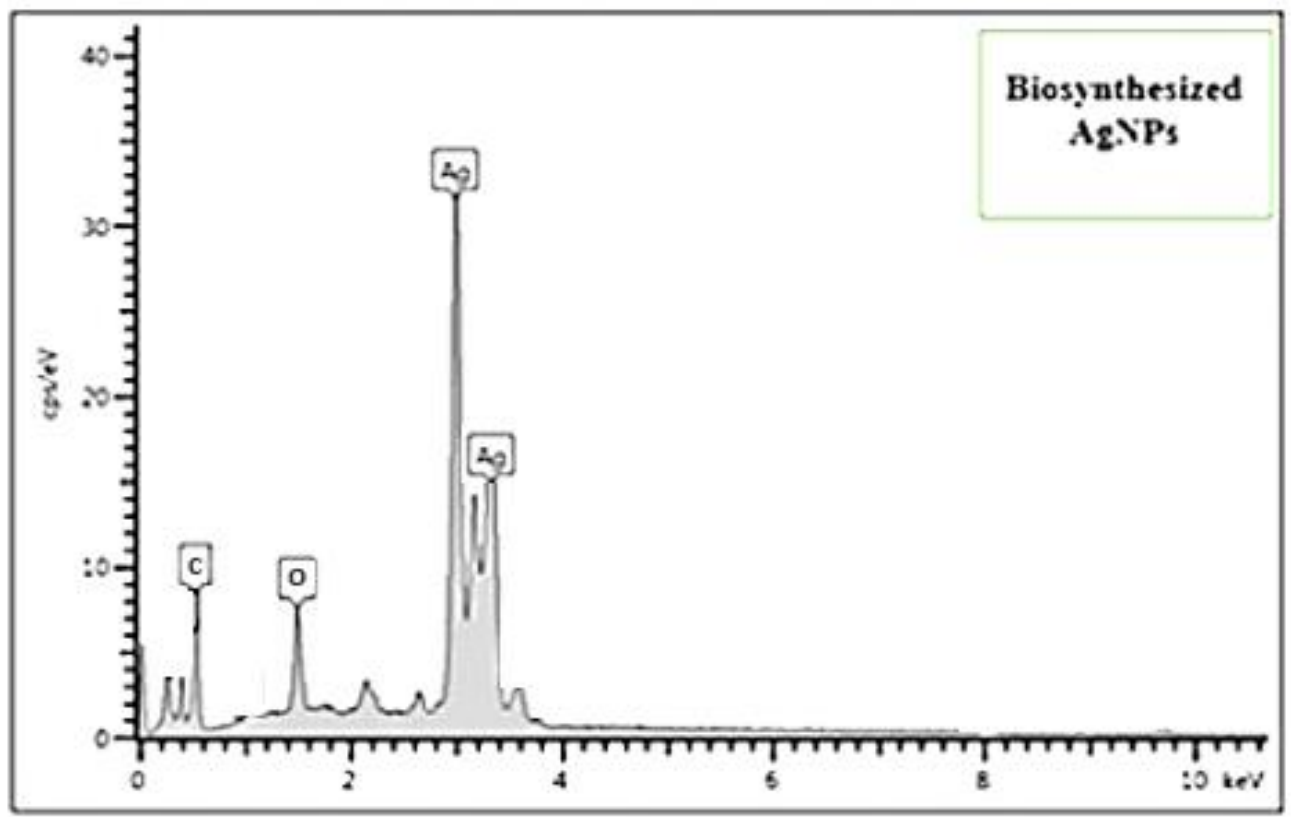

Figure 5: EDX image of the synthesized silver nanoparticles

\section{XRD Analysis of Synthesized Silver Nanoparticles}

The XRD pattern in Figure 6 revealed three distinctive diffraction peaks of $38.07,44.25$, and $76.71 \theta$ at $2 \theta$ values indexed to the (111), (200), and (311) reflection planes of face centered cubic structure of silver. This confirmed that the synthesized silver nanoparticles are crystalline in nature. The occurrence of these peaks also ascertained that the extract contain some organic compounds that are responsible for the reduction of silver ions and stabilization of resultant nanoparticles. The data obtained from the XRD pattern is similar to the finding of [18].

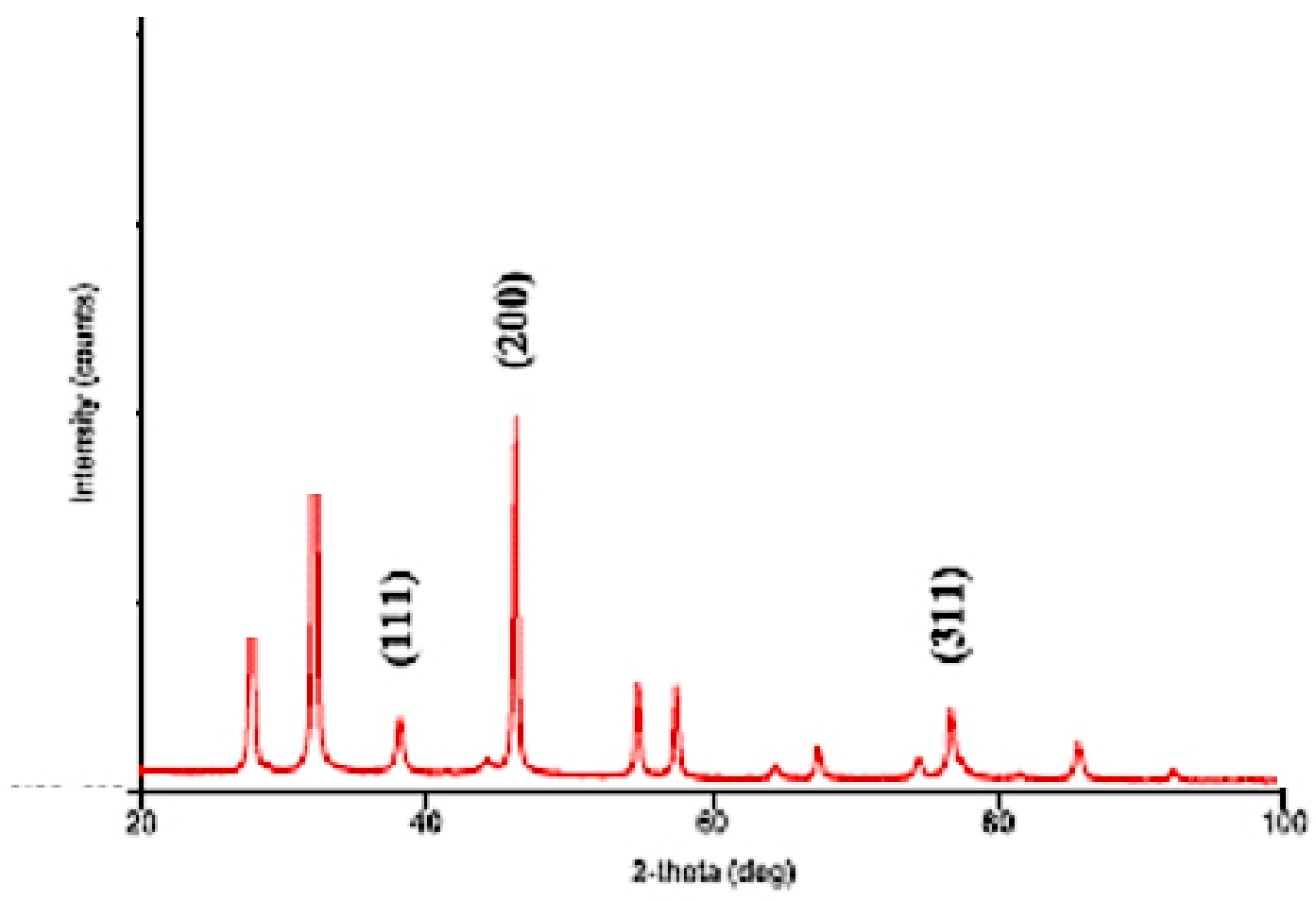

Figure 6: XRD pattern in synthesized silver nanoparticles 


\section{Antibacterial Activities of Synthesized Silver} Nanoparticles

The result obtained from the investigation of the antibacterial activity of AgNPs was presented in Figure 7. The zones of inhibition displayed by the AgNPs against test bacteria ranges from 26 to $6 \mathrm{~mm}$ while the zones of inhibition displayed by the control against Staphylococcus aureus, Bacillus cereus, Pseudomonas aeruginosa and Escherichia coli were 20,27, 30 and $29 \mathrm{~mm}$ respectively. The results obtained showed the efficacy of AgNPs in inhibiting the growth of test bacteria at all concentrations with varying potency. The highest effectiveness of the AgNPs against test bacteria was observed at the concentration of $150 \mathrm{mg} / \mathrm{ml}$. The order of effectiveness of the AgNPs against test bacteria was given as Pseudomonas aeruginosa $>$ Escherichia coli $>$ Bacillus cereus $>$ Staphylococcus aureus with inhibition zones of 26, 24, 16 and $14 \mathrm{~mm}$ respectively. This suggested that Pseudomonas aeruginosa was more susceptible to the AgNPs while Staphylococcus aureus had most resistance to the AgNPs. Judging from this experiment the AgNPs had more effectiveness on Gram negative bacteria compare to Gram Positive strains of bacteria. The thick cell wall exhibited by Gram Positive bacteria might be responsible for this finding. The result of this study correspond to the findings of $[19,20]$.

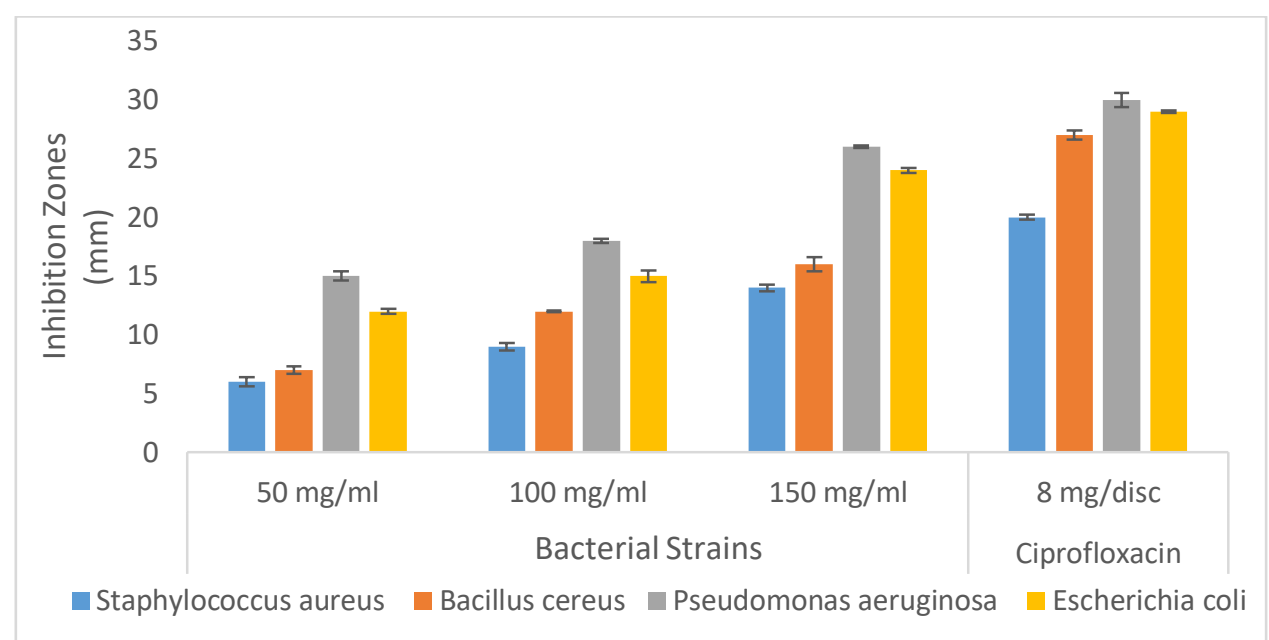

Figure 7: Antibacterial screening of different concentrations of AgNPs

\section{CONCLUSION}

Conclusively, a safe and easy method of synthesizing silver nanoparticles was achieved using Garcinia kola leaf extract as reducing and stabilizing agent. The antibacterial investigation confirmed the efficacy of synthesized AgNPs in inhibiting the growth of tested bacteria. This study provide scientific information that can be useful to pharmaceutical agencies in production of antibacterial drugs capable of combating bacterial infection that have developed resistance against existing antibiotic drugs.

\section{REFERENCES}

[1] Franci G, Falanga A, Galdiero S, Palomba L., Rai M Silver nanoparticles as potential antibacterial agents. Mol. 2015; 20:8856-8874

[2]Mallevre F, Fernandes TF, Aspray TJ. Pseudomonas putida biofilm dynamics following a single pulse of silver nanoparticles. Chemosph. 2016; 153:356-364

[3] Guzmán MG, Dille J, Godet S. Synthesis of silver nanoparticles by chemical reduction method and their antibacterial activity. Int J Chem Biomol Eng. 2009; 2(3):104-11.

[4] Song KC, Lee Sm, Park TS Lee BS. Preparation of colloidal silver nanoparticles by chemical reduction method. Korean J Chem Eng. 2009; 26 (1):153-5.

[5] Rashid MU, Bhuiyan MKH, Quayum ME. Synthesis of silver nano particles (Ag-NPs) and their uses for quantitative analysis of vitamin C tablets. Dhaka Univ J Pharm Sci. 2013; 12(1):29-33.

[6] Qin Y, Ji X, Jing J, Liu H, Wu H, Yang W. Size control over spherical silver nanoparticles by ascorbic acid reduction. Colloids Surf A Physicochem Eng Asp. 2010; 372 (1-3):172-6.
[7] Kowshik M, Ashtaputre S, Kharrazi S, Vogel W, Urban J Kulkarni, S.K, Paknikar K.M. Extracellular synthesis of silver nanoparticles by a silver-tolerant yeast strain MKY3. Nanotech. 2002; 14 (1):95.

[8] Natarajan K, Selvaraj S, Murty VR. Microbial production of silver nanoparticles. Dig J Nanomater Biostruct. 2010; 5(1):135-40.

[9] Prakash P, Gnanaprakasam P. Emmanuel R. Saravanan M. Green synthesis of silver nanoparticles from leaf extract of Mimusops elengi, Linn for enhanced antibacterial activity against multi drug resistant clinical isolates. Colloids Surf B: Biointer. 2013; 108:255-9

[10] Antonio Z, Annalaura I, Stefano N and Roberto L Green Synthesis of Silver Nanoparticles Using Bilberry and Red Currant Waste Extracts. Proc. 2019; 7, 193; 1-12

[11] Abudalo MA, Al-Mheidat IR, Al-Shurafat AW, Grinham C, Oyanedel-Craver V. Synthesis of silver nanoparticles using a modified Tollens' method in conjunction with phytochemicals and assessment of their antimicrobial activity. Peer J. 2019; 1-22

[12] Balavijayalakshmi J., Ramalakshmi V 2019. Carica papaya peel mediated synthesis of silver nanoparticles and its antibacterial activity against human pathogens. J Appl Res Techn 2017; 413422

[13] Folorunso A, Akintelu S, Oyebamiji AK, Ajayi S , Abiola B , Abdusalam I , Morakinyo A, Biosynthesis, characterization and antimicrobial Activity of gold nanoparticles from leaf extracts of Annona muricata. J Nanostru. Chem. 2019;111-117

[14] Akintelu SA, Folorunso AS. Characterization and Antimicrobial Investigation of Synthesized Silver Nanoparticles from Annona muricata Leaf Extracts. HSOA Journal of Nanotechnology: Nanomedicine \& Nanobiotechnology 2019; 6: 1-5.

[15] Jerushka S M, Suresh B N K, Karen P, Sershen and Patrick G. Adv Nat Scis: Nanosci Nanotech. 2018; 1-9 
[16] Akhil R, Jyoti R and Mira D. Green synthesis of silver nanoparticles from Tectona grandis seeds extract: characterization and mechanism of antimicrobial action on different microorganisms. J Anal Sci Techn. 2019; 1-10

[17] El-Saadony MT, El-Wafai NA, El-Fattah HIA, Mahgoub SA . Biosynthesis, optimization and characterization of silver nanoparticles using a soil isolate of Bacillus pseudomycoides MT32 and their antifungal activity against some pathogenic fungi. Adv. Anim. Vet. Sci. 2019; 7(4): 238-249.

[18] Saba P, Maryam G, Saeid B. Green synthesis of silver nanoparticles using the plant extract of Salvia spinosa grown in vitro and their antibacterial activity assessment. J Nanostru Chem 2019; 9:1-9

[19] Oyebamiji A K, Akintelu S A, Folorunso A S., Abiola B E., Ajayi Samuel O., Abdusalam I O., and Morakinyo A E. Computational And Experimental Studies On Antimicrobial Activity Of The Bark Of Annona Muricata Against Some Selected Human Pathogenic Bacteria And Fungi. Int J Mod Chem 2019; 11(1): 9-27
[20] Yohannes KE, Ebrahim AS, Tekleab T T, and Gedefaw GA. Antibacterial Potential of Aloe weloensis (Aloeacea) Leaf Latex against Gram-Positive and Gram-Negative Bacteria Strains. Int J Microbio. 2019;1-4

[21] Folorunso A.S, Oyebamiji A.K, Erazua E.A and Akintelu S.A. The Exploration of Antifungal Activity of Garcinia kola Seed as Novel Antifungal Agent. Int. J Trad Nat Med, 2019; 9(1): 41-49

[24] Akintelu S.A, Abiola B.E, Ajayi S.O and Olabemiwo O.M Quantification and Preliminary Estimation of Toxic Effects of Polycyclic Aromatic Hydrocarbon in Some Antimalarial Herbal Drugs in Southwest Nigeria. Bull Pharm Res. 2018; 8(1):152.

[23] Akintelu S.A, Abiola B.E, Ajayi S.O, Olabemiwo O.M (2019) Preliminary Study of the Effects of some Herbal Drugs on the Heamatological and Biochemical Parameter of Winster Albino Rats. Int J Sci. 2019; 8(10) 26-31 